\title{
Gastroparesis among Type 1 and Type 2 Diabetic Patients in the United Arab Emirates
}

\author{
Gassan Darwiche ${ }^{1}$, Safaa Kasim Mohammed2 ${ }^{2}$, Nesreen Aldawi ${ }^{3}$, Sijomol Skaria ${ }^{3}$, \\ Yohannes Tesfa ${ }^{3}$ \\ ${ }^{1}$ Department of Internal Medicine, Skane University Hospital, Lund University, Lund, Sweden \\ ${ }^{2}$ Department of Radiology, Sheikh Khalifa Hospital, Ajman, United Arab Emirates \\ ${ }^{3}$ Rashid Centre for Diabetes and Research, Ajman, United Arab Emirates \\ Email: "ghassan.darwiche@med.lu.se
}

Received 26 February 2014; revised 20 March 2014; accepted 28 March 2014

Copyright (C) 2014 by authors and Scientific Research Publishing Inc.

This work is licensed under the Creative Commons Attribution International License (CC BY). http://creativecommons.org/licenses/by/4.0/

c) (7) Open Access

\section{Abstract}

Aims: Delayed gastric emptying (GE) may have a major effect on the management of diabetic patients by causing upper gastrointestinal symptoms, impaired oral drug absorption and contributing to poor blood sugar control. Although the United Arab Emirates (UAE) has one of the highest prevalence of diabetes in the world, studies focusing on the prevalence of diabetes gastroparesis among these diabetics have never been reported previously. The aim of this study was to investigate gastroparesis among randomly selected Emirati type 1 and type 2 diabetic patients referred to a national diabetes center in the UAE. Methods: The study was designed as a controlled, single-blinded study. Using a standardized ultrasound technique, GE was studied in thirty-one randomly recruited type 1 and type 2 diabetic patients and ten normal healthy volunteers. The gastric emptying rate (GER) was estimated and expressed as the percentage reduction in antral cross-sectional area from 15 to 90 min after the ingestion of a semisolid breakfast meal. Results: In comparison to healthy volunteers, diabetic patients showed overall significantly wider mean values of the fasting as well as the postprandial antral areas. The mean value of GER in these Emirati diabetic patients was estimated at $17 \%$, which was less than half of that in the healthy volunteers $(50 \%)$. Statistically the difference was highly significant $(p<0.001)$. Normal gastric emptying was estimated as of GER $>32 \%$. Consequently, 71\% (22 of 31) of the diabetic patients in this study had more or less pronounced delays in GER (gastroparesis). Conclusions: The results from the present study indicate a higher prevalence of gastroparesis among randomly selected Emirati type 1 and type 2 diabetic patients, than in any other study previously published around the world. This is in line with previous reports about the high prevalence of diabetes complications among UAE diabetics. A larger study is needed to confirm these results.

\footnotetext{
${ }^{*}$ Corresponding author.
} 


\section{Keywords}

\section{Diabetes Mellitus, Gastric Emptying, Ultrasonography, United Arab Emirates}

\section{Introduction}

Impaired gastric function is a complication to diabetes that is common throughout the diabetes population. Several cross-sectional studies have shown that disturbed gastric emptying (GE), including delayed GE (gastroparesis), is frequent among diabetics, indicating a prevalence of $30 \%-50 \%$ among type 1 as well as type 2 diabetic patients [1]-[6]. Abnormal gastric motor function may have a major effect on the management of diabetic patients by causing upper gastrointestinal symptoms, impaired oral drug absorption and contributing to poor control of blood glucose concentrations due to the delayed uptake of glucose in the intestines causing a mismatch with the anti-diabetic treatment [7] [8].

Gastroparesis, which is defined as a delayed gastric emptying which cannot be explained by mechanical obstruction, can be caused by a wide range of disorders, e.g. infections, surgery, systemic illnesses and eating disorders. Diabetic gastroparesis is caused mainly by a vagal autonomic neuropathy, but hormonal imbalance has also been proposed to be involved in the pathogenesis [9]. Patients with gastroparesis may experience symptoms in the upper gastrointestinal (GI) tract connected to meal digestion. Typically these include postprandial early satiety, filling sensation, abdominal pain, nausea and vomiting. The relationship between delay in GE in patients with diabetes mellitus (DM) and the presence or absence of upper gastrointestinal symptoms is relatively poor [2]-[4] [6]. Actually, it has been shown that up to $50 \%$ of patients with marked delay in GE have few or no upper gastrointestinal symptoms making it difficult to identify patients with gastroparesis on clinical grounds [2] [7] [10]. Because the predictive value of symptoms of this condition is poor, objective measurement is required for the diagnosis of disordered gastric motility.

For type 2 diabetes, the gastric emptying rate seems to be a dynamic process. There is evidence that early in the course of type 2 diabetes, there is an increased gastric emptying rate in many patients [11] [12]. This phase is followed by progressive slowing of the gastric emptying [13]. GLP-1 (glucagon-like-peptide-1, an incretin) receptor agonists are a new type of anti-diabetic medications. They increase the postprandial insulin release, decrease the glucagon secretion and glucose release from the liver, reduce appetite as well as cause slower gastric emptying [14]. To prevent exacerbation of GI symptoms, it would be of importance to determine if a patient has gastroparesis before initiating incretin-based therapy. Whereas the ability of a GLP-1 receptor agonist to slow gastric emptying would be beneficial when the gastric emptying rate is rapid, it would likely be harmful in patients with type 2 diabetes mellitus who develop diabetic gastroparesis.

United Arab Emirates (UAE) has one of the highest prevalence of diabetes in the world. There is an alarming increase, and the diabetic population among the UAE is predicted to consist of a quarter of the national population [15]-[17]. Although gastroparesis is a common complication to diabetes, studies focusing on the prevalence of diabetes gastroparesis have never been done previously in the UAE. Taking this into consideration, the purpose of this study was to investigate gastroparesis among randomly selected Emirati type 1 and type 2 diabetic patients referred to a national diabetes center in the UAE.

\section{Material and Methods}

\subsection{Healthy Volunteers}

A control group of ten healthy volunteers of whom two were smokers (8 men and 2 women: mean age $54 \pm 14$ years; range 29 - 73 years: mean BMI $29.9 \pm 9.2 \mathrm{~kg} / \mathrm{m}^{2}$; range $20.7-48.0 \mathrm{~kg} / \mathrm{m}^{2}$ ), (Table 1), was used as a reference for normal gastric emptying. None of these healthy volunteers proved to have symptoms or a prior history of gastrointestinal disease, abdominal surgery (except for appendectomy) or diabetes mellitus. The volunteers had no psychiatric diseases, connective tissue diseases, cerebrovascular or endocrine diseases, nor were they receiving any drugs likely to interfere with gastric activity, including birth control medication. On each study day all current symptoms attributable to the gastrointestinal tract were recorded, and the fasting blood glucose checked for normal concentrations using finger-prick capillary blood samples. If the subject reported 
Table 1. Data on healthy volunteers and diabetic patients.

\begin{tabular}{ccc}
\hline & Healthy volunteers $(\boldsymbol{n}=\mathbf{1 0})$ & Diabetic patients $(\boldsymbol{n}=\mathbf{3 1})$ \\
\hline Sex $(\mathrm{F})$ & $2(20 \%)$ & $6(19 \%)$ \\
Age $($ year $)$ & $54 \pm 14(29-73)$ & $52 \pm 12(23-76)$ \\
BMI $\left(\mathrm{kg} / \mathrm{m}^{2}\right)$ & $29.9 \pm 9.2(20.7-48.0)$ & $29.5 \pm 3.7(24.6-41.2)$ \\
Smokers $(n)$ & $2(20 \%)$ & $7(23 \%)$ \\
Diabetes type $1 / 2$ & - & $4 / 27$ \\
Duration of diabetes (year) & - & $15 \pm 9(1-32)$ \\
GER (\%) & $50 \pm 18(21-76)^{\dagger}$ & $17 \pm 19(0-57)$ \\
Symptoms of gastroparesis & - & $14(45 \%)$ \\
HbA1c (\%) & - & $8.6 \pm 1.5(6.1-13.4)$ \\
Complications (n) & - & $14(45 \%)$ \\
Retinopathy & - & $9(29 \%)$ \\
Nephropathy & - & $12(39 \%)$ \\
Peripheral neuropathy & - & $2(6 \%)$ \\
Diabetic foot & - & $7(23 \%)$ \\
History of IHD & - & \\
\hline
\end{tabular}

BMI = Body Mass Index, GER = Gastric Emptying Rate, HbA1c = glycosylated haemoglobin, IHD = Ischaemic Heart Disease. Age, BMI, duration, and HbA1c are given as means \pm SD with range in parentheses. Absence of superscript indicates no significant difference between healthy volunteers and diabetic patients. $\dagger$ indicate highly significant difference $(p<0.001)$ in GER between the group of healthy volunteers and diabetic patients.

symptoms indicating constipation or diarrhoea the examination was postponed. The participants gave their informed consent before the study began and knew that they could withdraw from the study at any time.

\subsection{Diabetic Patients}

The study was conducted at the Rashid Centre for Diabetes and Research (RCDR), a national reference centre for diabetes and obesity treatment and research in the emirate of Ajman. Thirty-one randomly recruited type 1 and type 2 diabetic patients ( 6 women and 25 men: mean age $52 \pm 12$ years; range 23 - 76 years: mean BMI 29.5 $\pm 3.7 \mathrm{~kg} / \mathrm{m}^{2}$; range $24.6-41.2 \mathrm{~kg} / \mathrm{m}^{2}$ : mean duration of diabetes $15 \pm 9$ years; range 1 - 32 years and mean HbA1c 8.6\% + 1.5\%; range 6.1\% - 13.4\%), (Table 1), at RCDR, were examined. Seven smokers were identified, all men. Four patients had type 1 diabetes mellitus and the remaining 27 type 2 diabetes mellitus. The patients were from all the emirates in the UAE, but predominantly from the northern emirates. Seven patients had a history of ischemic heart disease (IHD), twelve patients had neuropathy, fourteen had retinopathy, two were diagnosed with diabetic foot ulcers and nine showed signs of nephropathy, without uremia (Table 2). The patients had no history of prior gastric outlet obstruction, connective tissue diseases or gastrointestinal surgery (except for appendectomy). No patients were receiving any medication likely to interfere with gastric activity. On each study day all current symptoms, attributable to the gastrointestinal tract, were noted. Patients reporting acute temporary abnormal defecation, such as constipation or diarrhoea were examined on another day on condition that the abnormal defecation was normalized. On the other hand, patients with chronic constipation (in our study defined as symptoms for one year or longer) were not excluded as this was assumed to be their basal state, possibly due to autonomic neuropathy [18]. Fourteen patients reported daily or weekly symptoms suggestive of diabetic gastroparesis (Table 1). However, the diabetic patients were not selected based on the individual probability of gastroparesis since the relationship between gastroparesis and symptoms of gastroparesis is poor, as explained previously. All patients were given written information prior to the study and were aware of their option to withdraw from the study at any time they desired.

\subsection{Test Procedure}

The study was designed as a controlled, single-blinded study and conducted in 2011-2012. Data was collected through patient interviews, anthropometric data, lab tests and ultrasound measurements. Data collection for the diabetic patients also included information about diabetes duration and the type of diabetes, the current 
Table 2. Data on diabetic patients with and without gastroparesis.

\begin{tabular}{|c|c|c|}
\hline & \multicolumn{2}{|c|}{ Diabetic patients } \\
\hline & With gastroparesis $(n=22)$ & Without gastroparesis $(n=9)$ \\
\hline $\operatorname{Sex}(F)$ & 6 & 0 \\
\hline Age (year) & $51 \pm 14(23-76)$ & $55 \pm 9(36-67)$ \\
\hline $\operatorname{BMI}\left(\mathrm{kg} / \mathrm{m}^{2}\right)$ & $29.5 \pm 4.1(24.6-41.2)$ & $29.4 \pm 3.0(25.0-34.4)$ \\
\hline Smokers $(n)$ & $4(18 \%)$ & $3(33 \%)$ \\
\hline Diabetes type $1 / 2$ & 3/19 (14\%) & 1/8 (11\%) \\
\hline Duration of diabetes (year) & $13 \pm 8(1-32)$ & $19 \pm 10(4-31)$ \\
\hline GER (\%) & $7 \pm 10(0-31)^{\dagger}$ & $42 \pm 10(33-57)$ \\
\hline Fasting antral area $\left(\mathrm{mm}^{2}\right)$ & $686 \pm 196(369-1033)^{a}$ & $1102 \pm 359(638-1472)$ \\
\hline Antral area $15 \mathrm{~min}\left(\mathrm{~mm}^{2}\right)$ & $1248 \pm 393(724-1969)^{b}$ & $1689 \pm 363(1088-2385)$ \\
\hline Antral area $90 \mathrm{~min}\left(\mathrm{~mm}^{2}\right)$ & $1299 \pm 340(680-1999)^{c}$ & $962 \pm 209(568-1237)$ \\
\hline Symptoms of gastroparesis & $10(45 \%)$ & $4(44 \%)$ \\
\hline HbA1c (\%) & $8.6 \pm 1.7(6.1-13.4)$ & $8.4 \pm 1.3(6.8-10.8)$ \\
\hline \multicolumn{3}{|l|}{ Complications $(n)$} \\
\hline Retinopathy & $11(50 \%)$ & $3(33 \%)$ \\
\hline Nephropathy & $7(32 \%)$ & $2(22 \%)$ \\
\hline Peripheral neuropathy & $10(45 \%)$ & $2(22 \%)$ \\
\hline Diabetic foot & $2(9 \%)$ & 0 \\
\hline History of IHD & $5(23 \%)$ & $2(22 \%)$ \\
\hline
\end{tabular}

BMI = Body Mass Index, GER = Gastric Emptying Rate, HbA1c = glycosylated haemoglobin, IHD = Ischaemic Heart Disease. Age, BMI, duration, and HbA1c are given as means \pm SD with range in parentheses. ${ }^{a}$ indicate significant difference $(p=0.017),{ }^{b}$ indicate significant difference $(p=$ $0.016),{ }^{\text {C }}$ indicate significant difference $(p=0.006)$ and $\dagger$ highly significant difference $(p<0.001)$ between diabetic patients with gastroparesis and those without gastroparesis. Absence of superscript indicates no significant difference.

anti-diabetic treatment and other medications, current $\mathrm{HbA1c}$ value and the presence of diabetes complications including retinopathy, nephropathy, peripheral neuropathy, diabetic foot and history of IHD. All subjects were examined in the morning, following an 8-hour fast. Smoking was prohibited 8 hours before and during the test. On the day of the study all volunteers were checked for normal fasting blood glucose concentration. The diabetic patient's blood glucose concentrations were also measured in the morning before examination. In order to avoid confounding influence by the blood glucose, measurements of gastric emptying in the diabetic group were done on condition that the fasting blood glucose level was $4.0-9.0 \mathrm{mmol} / \mathrm{l}$. Analyses were made using Roche cobas 6000 (Roche, Switzerland), which gives an HbA1c percentage according to DCCT.

Using a questionnaire, the patients were asked about upper gastrointestinal symptoms (such as dysphagia, regurgitation, heartburn, postprandial early satiety, abdominal fullness, nausea, vomiting), and lower gastrointestinal symptoms (such as diarrhoea and constipation) on the morning of the examination. Symptoms suggestive of diabetic gastroparesis were defined as postprandial early satiety, abdominal fullness, nausea or vomiting. Early satiety was defined as the premature sensation of postprandial abdominal fullness, and abdominal fullness as an unpleasant sensation like the persistence of food in the stomach. Nausea was defined as the sensation of epigastric or abdominal queasiness that typically precedes frank vomiting, and vomiting as the forceful ejection of gastric contents through the mouth, as distinct from regurgitation. The report of one or more of these symptoms signified symptoms of gastroparesis. The study was performed according to the Helsinki declaration and approved by the research ethics committee of Al Qassimi Hospital in Sharjah, UAE.

\subsection{Assessment of Gastric Emptying}

Gastric emptying was assessed using a standardized ultrasound method [19] [20]. The patients were examined with a Philips iU22 ultrasound equipment (Royal Philips Electronics, The Netherlands). The probe used was a convex abdominal $5 \mathrm{MHz}$ transducer. After an overnight fasting each subject was given a test meal consisting of $300 \mathrm{~g}$ of rice pudding (Al Rawabi Dairy Company, Dubai, UAE) to be ingested within 5 min. Total caloric value 
was $420 \mathrm{kcal}$, provided as $11 \%$ protein, 58\% carbohydrate, and 31\% fat. During the examination all subjects were in the supine position with the ultrasound transducer applied with minimal abdominal compression. Between examinations the subjects rested seated. The tests were run in the same environment at the same time in the morning. Ultrasound measurements were performed by two radiologists (EAS and SKM), who were blinded as to whether each participant was a diabetic patient or a healthy volunteer.

The reduction of the antral area over time was used as an estimation of gastric emptying. Measurements were carried out before meal intake, as well as 15 and 90 minutes after the end of meal ingestion. The cross-sectional area of the antrum was determined by measuring both the longitudinal $\left(D_{1}\right)$ and anteroposterior $\left(D_{2}\right)$ diameter. A longitudinal scan at the level of the abdominal aorta and the left lobe of the liver was used as a landmark for orientation. This assured a consistency of the scanning method throughout the study. Measurements of the gastric antrum was made from the outer profile of the wall and performed between antral contractions to capture the relaxed width of the antrum. Since inspiration and expiration may cause changes in antral diameters, measurements were taken in the same state of breathing for each patient. At each observation, three measurements were done using the mean values of the longitudinal $\left(D_{1 \text { mean }}\right)$ and anteroposterior $\left(D_{2 \text { mean }}\right)$ diameters to calculate the fasting, 15 and 90 minutes postprandial antral area. The antral cross-sectional area $\left(A_{\text {Antrum }}\right)$ was calculated using the following formula: $A_{\text {Antrum }}=\left(\Pi \times D_{1 \text { mean }} \times D_{2 \text { mean }}\right) / 4$. GER was estimated and expressed as the percent reduction in antral cross-sectional area from 15 to $90 \mathrm{~min}$ after meal ingestion calculated as follows: GER $=\left[1-\left(A-\right.\right.$ area $^{90 \mathrm{~min}} / A-$ area $\left.\left.^{15 \mathrm{~min}}\right)\right] \times 100$. In the cases where the antral area continued to increase between 15 and 90 minutes, the calculated GER would be a negative percentage. The GER in these cases was set to zero.

\subsection{Statistical Analysis}

Descriptive data, such as age, BMI, diabetes duration and HbA1c as well as measurements of the antral areas and GER are presented as mean values \pm SD and range. Mann-Whitney $U$ test was used for intergroup and intragroup comparisons. The GER in healthy volunteers was used to calculate the limit for normal gastric emptying using a one-sided 95\% confidence interval (mean GER - $1.64 \times \mathrm{SD}$ ). All statistical calculations were performed in IBM SPSS Statistics, version 22, 2013. $P$-values $<0.05$ were considered significant and $p<0.001$ as highly significant.

\subsection{Role of the Funding Source}

The sponsor of the study had no role in study design, data collection, data analysis, data interpretation, or writing of the report. The corresponding author had full access to all the data in the study and had final responsibility for the decision to submit for publication.

\section{Results}

There was no significant difference between the group of healthy volunteers and the diabetic patients regarding sex, age, BMI and smoking habits (Table 1).

\subsection{Healthy Volunteers}

The mean value of the fasting antral cross-sectional area was $373 \pm 145(180-659) \mathrm{mm}^{2}$. The postprandial antral cross-sectional areas were $813 \pm 178(594-1184) \mathrm{mm}^{2}$ and $405 \pm 164$ (196 - 721) 15 and 90 minutes, respectively, after the end of the meal (Figure 1). The mean value of GER was estimated to be $50 \pm 18$ (21 - 76)\%. Assuming that the GER in healthy volunteers had a normal distribution (mean GER $50 \pm 18 \%$ and median GER $50 \%$ ) a limit could be calculated using a one-sided $95 \%$ confidence interval (mean GER $-1.64 \times$ SD) indicating that GER $<32 \%$ should be regarded as delayed.

\subsection{Patients with Diabetes}

The mean antral cross-sectional area prior to meal ingestion was $811 \pm 314(369-1472) \mathrm{mm}^{2}$. The 15 and 90 min postprandial antral cross-sectional areas were $1376 \pm 429(724-2385) \mathrm{mm}^{2}$ and $1201 \pm 342(568-1999)$ $\mathrm{mm}^{2}$, respectively. The mean value of GER in the diabetic patients was estimated by $17 \pm 19(0-57) \%$. A highly significant difference was found between healthy volunteers and diabetic patients $(p<0.001)$, in GER 
(Table 1, Figure 2). Assuming that GER < 32\% indicate a delayed gastric emptying, about 71\% (22 of 31) of the diabetic patients in this study had a more or less pronounced delays in GER (gastroparesis).

Age, BMI, smoking habits, type of diabetes, the glycaemic control (HbA1c) or the mean duration of diabetes did not differ significantly between the two subgroups of diabetic patients with and without gastroparesis (Table 2). Although there appeared to be a preponderance of diabetes-related complications in the group with diabetic gastroparesis, it was not proven statistically significant in this study (Table 2). Ten of the 22 patients with gastroparesis and four of the nine patients without gastroparesis had symptoms suggestive of diabetic gastroparesis. There was no significant correlation between gastroparesis and symptoms suggestive of diabetic gastroparesis. Table 2 also shows that, by selection, the GER was significantly lower $(p<0.001)$ in the subgroup of diabetics with gastroparesis than in those without gastroparesis.

Diabetic patients with gastroparesis showed significantly greater $(p=0.001)$ fasting antral areas $(686 \pm 196$, range $369-1033 \mathrm{~mm}^{2}$ ) compared with healthy volunteers (373 \pm 145 , range $180-659 \mathrm{~mm}^{2}$ ), (Figure 1). The postprandial cross-sectional areas were also significantly greater in diabetics with gastroparesis compared with healthy volunteers, showing $1248 \pm 393(724-1969) \mathrm{mm}^{2}$ vs. $813 \pm 178(594-1184) \mathrm{mm}^{2},(p=0.001)$, and $1299 \pm 340(680-1999) \mathrm{mm}^{2}$ vs. $405 \pm 164(196-721) \mathrm{mm}^{2},(p<0.001)$, after 15 and 90 minutes, respectively (Figure 1). As compared to diabetic patients with gastroparesis, diabetic patients without gastroparesis showed significantly larger mean values for the fasting antral area $(p=0.017),\left(1102 \pm 359\right.$, range $638-1472 \mathrm{~mm}^{2}$ vs. $686 \pm 196$, range $\left.369-1033 \mathrm{~mm}^{2}\right)$ and the postprandial antral area at $15 \min (p=0.016),(1689 \pm 363$, range $1088-2385 \mathrm{~mm}^{2}$ vs. $1248 \pm 393$, range $724-1969 \mathrm{~mm}^{2}$ ), (Table 2, Figure 1). Despite starting with greater fasting antral areas and showing larger 15 min postprandial antral areas, diabetic patients without gastroparesis manage to reduce the postprandial $90 \mathrm{~min}$ antral area $\left(962 \pm 209\right.$, range $568-1237 \mathrm{~mm}^{2}$ ) even below the fasting antral area (Table 2, Figure 1). Diabetic patients with gastroparesis however tended to remain at the same mean areas 15 and 90 minutes after the meal (1248 \pm 393, range 724 - 1969 vs. $1299 \pm 340$, range $680-1999$ mm²), (Figure 1).

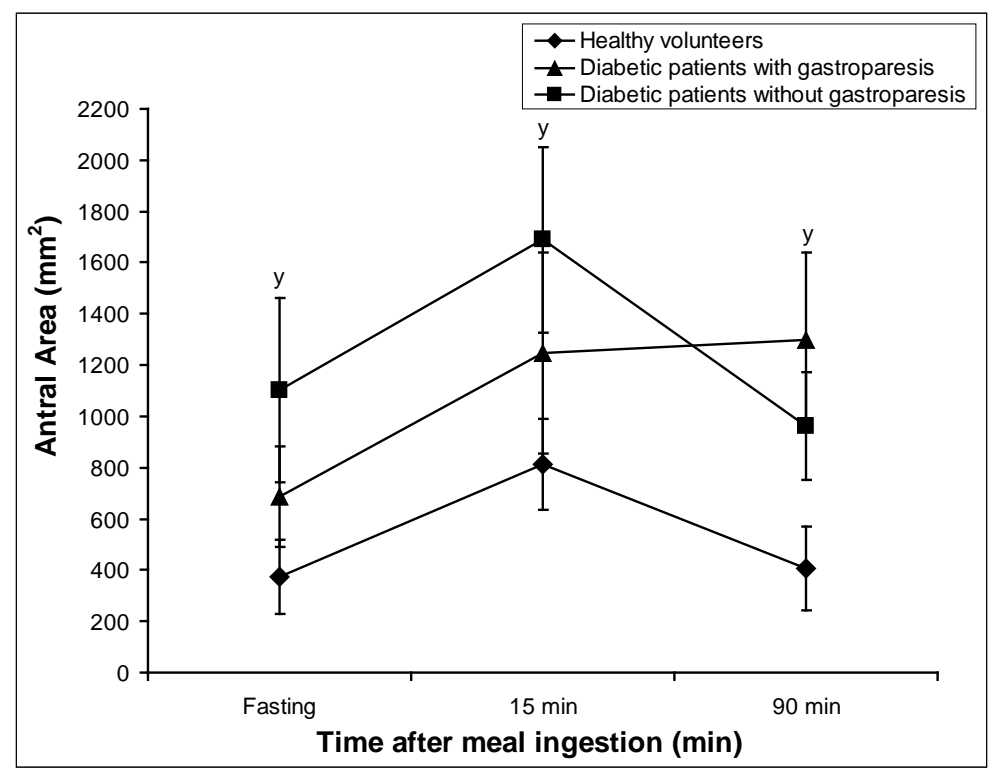

Figure 1. Fasting and postprandial gastric antral cross-sectional areas in healthy volunteers $(n=10)$, diabetic patients with gastroparesis $(n=22)$ and diabetic patients without gastroparesis $(n=9)$. The Mean \pm SD values are shown. ${ }^{\mathrm{y}}$ indicate significant differences in the antral areas between healthy volunteers and diabetic patients with gastroparesis (fasting $=0.001,15 \mathrm{~min}=$ $0.001,90 \mathrm{~min}<0.001$ ), healthy volunteers and diabetic patients without gastroparesis (fasting $=0.002,15 \mathrm{~min}<0.001$, $90 \mathrm{~min}<0.001$ ) as well as between diabetic patients with gastroparesis and those without gastroparesis (fasting $=0.017,15 \mathrm{~min}=0.016,90 \mathrm{~min}=0.006)$, (Mann-Whitney U test). 


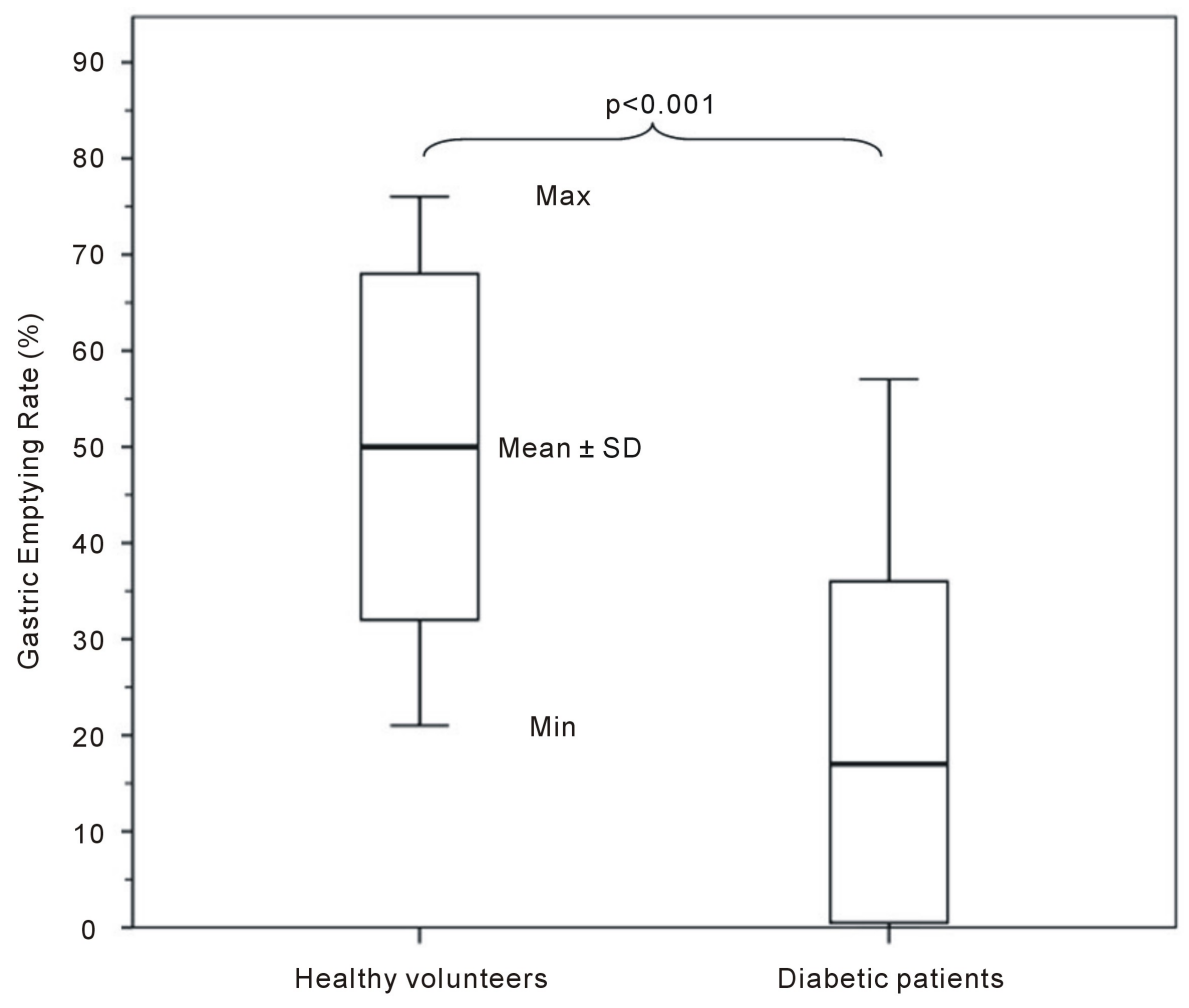

Figure 2. Gastric Emptying Rate (GER) in healthy volunteers $(\mathrm{n}=10)$ and diabetic patients (n $=31$ ). The Mean \pm SD, minimum (Min), and maximum (Max) values are shown. The difference in GER was highly significant between healthy volunteers and diabetic patients $(p<$ 0.001), (Mann-Whitney U test).

\section{Discussion}

Gastroparesis, or chronic delayed gastric emptying without mechanical obstruction, is common among patients with diabetes mellitus and is reported to occur in $30 \%-50 \%$ of the patients [1]-[6]. Although UAE has one of the highest prevalence of diabetes in the world there are no data on gastroparesis among the country's diabetic population. The results from the present study indicate a higher prevalence of gastroparesis (71\%) among randomly selected Emirati type 1 and type 2 diabetic patients, than in any other study previously published around the world. This is in line with previous reports about the high prevalence of diabetes complications among UAE diabetics [16]. The mean value of GER in the Emirati diabetic patients was estimated to be $17 \%$, which is less than half the rate in the healthy volunteers $(50 \%),(p<0.001)$. In a study on Swedish diabetic patients, using the same standardized ultrasound method for gastric assessment [19], the median GER was higher (29\%) than the one reported in this study (17\%), even though the Swedish patients were selected for clinically suspected gastroparesis. This could be explained by differences in caloric content of the test meals since the rate of gastric emptying is a function of the caloric density of the ingested meal [21]-[23]. Even if the quantity and energy distribution of test meals were the same in both studies, the total energy content differed. A lower caloric content in the Swedish rice pudding (330 kcal) compared to the one used in this study (420 kcal), thus might have influenced the gastric emptying causing a more rapid GER. Consequently, the limit for normal gastric emptying was set lower in our study compared to the Swedish study (32\% vs. $45 \%$ ), based on the gastric emptying data of the healthy volunteers. However, even after threshold corrections and despite the Swedish diabetics being high-risk patients selected to increase the probability to detect gastroparesis, the prevalence of delayed gastric emptying was lower (57\%) in Swedish diabetics compared to Emirati diabetic patients (71\%).

The results from the present study show that diabetes patients without gastroparesis start with a greater mean fasting antral area compared with diabetic patients with gastroparesis. Consequently, they also reach a greater maximal 15-minute postprandial antral area but still manage to reduce the mean antral area at 90 minutes even 
below the mean fasting antral area, while diabetic patients with gastroparesis seem to remain at the same mean areas 15 and 90 minutes after the meal (Table 2, Figure 1). The results are as expected and reflect a sustained normal postprandial gastric motor activity and gastric emptying in diabetic patients without gastroparesis. The vagus nerve activates the postprandial motility of the stomach and intestines by means of cephalic influences, gastric and intestinal tension receptors as well as intestinal chemoreceptors and the release of gut hormones [24] [25]. Thus, already the sight or chewing of food acts as a stimulus, so that the vagus nerve stimulates the production of gastric acid (the cephalic phase). It has been suggested that acid secretion is lower in some diabetic patients, probably due to vagal neuropathy [26] [27]. Such possible differences in gastric juice secretion between diabetic patients, with vagal neuropathy and gastroparesis, and diabetic patients without gastroparesis might explain the differences seen in the fasting antral areas in the present study. This assumption supported the fact that 90 minutes after ingestion the mean antral area was smaller than it was prior to meal ingestion in diabetic patients without gastroparesis, probably due to emptying of gastric juice. As compared to healthy volunteers, diabetic patients in general showed significantly greater dilation of the gastric antrum giving larger mean values for pre- as well as postprandial antral areas (Figure 1). Observations have been made previously, showing a wide gastric antrum in patients with long-standing diabetes mellitus type 1 [28]. This difference could represent a loss of gastric tone in the group of diabetic patients as a consequence of vagal impairment due to autonomic neuropathy causing a generally more "slack" stomach. Possible differences in the gastric antral content of liquid during fasting between healthy volunteers and diabetic patients also could influence the results.

In this study there was no significant correlation between gastroparesis and symptoms suggestive of diabetic gastroparesis. This is consistent with previous study results showing a poor relationship between delay in gastric emptying in patients with diabetes mellitus and the presence or absence of upper gastrointestinal symptoms [2]-[4]. It is believed that diabetic gastroparesis may be asymptomatic due to visceral afferent neuropathy [29] and unexplained poor glycaemic control might be the only clue to the diagnosis [30] [31]. Autonomic nervous function is reduced with age and could potentially cause delayed gastric emptying. However, studies have shown that this reduction is not large enough to be relevant [32]. Some studies have shown a difference between females and males regarding gastric emptying [33] [34] while others did not find any difference [19]. Obesity seems to be related to lower GLP levels and increased gastric emptying [35]-[37]. The mean BMI was high among the participants in this study which in theory could counteract the delayed gastric emptying of the diabetic patients. Despite this, the study shows low gastric emptying rates among Emirati diabetic patients and no significant relation was found between GER and the duration of diabetes, the HbA1c percentage, age or BMI. In addition, since age, sex, weight and smoking habits may affect gastric emptying, the control group was matched for these confounding factors. The limitations for this study are the small size of the diabetic patient group.

\section{Conclusion}

In conclusion, this study shows a higher rate of gastroparesis among randomly selected Emirati diabetic patients, than in any other study previously published around the world. A larger study is needed to confirm this high prevalence of gastroparesis among diabetic patients in the UAE.

\section{Authors' Contributions}

GD participated in the design of the study, recruitment of subjects, performance of statistical calculations and creation of the graphs, and drafting of the manuscript. YT participated in the design of the study, recruitment of subjects and drafting of the manuscript. Na and SS participated in recruitment of subjects and data collection. SKM participated in the design of the study and performance of the ultrasound examinations. All authors read and approved the final manuscript.

\section{Conflicts of Interest}

None of the authors had any personal or financial conflict of interest.

\section{Funding}

This study was supported by Rashid Centre for Diabetes and Research in Ajman, United Arab Emirates. 


\section{Acknowledgements}

This study was supported by Rashid Centre for Diabetes and Research in Ajman, United Arab Emirates. Technical assistance from Dr Eyad Al-Shari in the performance of ultrasound examinations is highly appreciated.

\section{References}

[1] Samsom, M., Vermeijden, J.R., Smout, A.J., et al. (2003) Prevalence of Delayed Gastric Emptying in Diabetic Patients and Relationship to Dyspeptic Symptoms: A Prospective Study in Unselected Diabetic Patients. Diabetes Care, 26, 3116-3122. http://dx.doi.org/10.2337/diacare.26.11.3116

[2] Horowitz, M., Maddox, A.F., Wishart, J.M., Harding, P.E., Chatterton, B.E. and Shearman, D.J. (1991) Relationships between Oesophageal Transit and Solid and Liquid Gastric Emptying in Diabetes Mellitus. European Journal of Nuclear Medicine, 18, 229-234. http://dx.doi.org/10.1007/BF00186645

[3] Wegener, M., Borsch, G., Schaffstein, J., Luerweg, C. and Leverkus, F. (1990) Gastrointestinal Transit Disorders in Patients with Insulin-Treated Diabetes Mellitus. Digestive Diseases, 8, 23-36. http://dx.doi.org/10.1159/000171237

[4] Keshavarzian, A., Iber, F.L. and Vaeth, J. (1987) Gastric Emptying in Patients with Insulin-Requiring Diabetes Mellitus. The American Journal of Gastroenterology, 82, 29-35.

[5] Lyrenas, E.B., Olsson, E.H., Arvidsson, U.C., Orn, T.J. and Spjuth, J.H. (1997) Prevalence and Determinants of Solid and Liquid Gastric Emptying in Unstable Type I Diabetes. Relationship to Postprandial Blood Glucose Concentrations. Diabetes Care, 20, 413-418. http://dx.doi.org/10.2337/diacare.20.3.413

[6] Horowitz, M., O’Donovan, D., Jones, K.L., Feinle, C., Rayner, C.K. and Samsom, M. (2002) Gastric Emptying in Diabetes: Clinical Significance and Treatment. Diabetic Medicine, 19, 177-194. http://dx.doi.org/10.1046/j.1464-5491.2002.00658.x

[7] Horowitz, M. and Fraser, R. (1994) Disordered Gastric Motor Function in Diabetes Mellitus. Diabetologia, 37, 543551. http://dx.doi.org/10.1007/BF00403371

[8] Shin, A.S. and Camilleri, M. (2013) Diagnostic Assessment of Diabetic Gastroparesis. Diabetes, 62, 2667-2673. http://dx.doi.org/10.2337/db12-1706

[9] Khoo, J., Rayner, C.K., Feinle-Bisset, C., Jones, K.L. and Horowitz, M. (2010) Gastrointestinal Hormonal Dysfunction in Gastroparesis and Functional Dyspepsia. Neurogastroenterology \& Motility, 22, 1270-1278. http://dx.doi.org/10.1111/j.1365-2982.2010.01609.x

[10] Punkkinen, J., Färkkilä, M., Mätzke, S., et al. (2008) Upper Abdominal Symptoms in Patients with Type 1 Diabetes: Unrelated to Impairment in Gastric Emptying Caused by Autonomic Neuropathy. Diabetic Medicine, 25, 570-577. http://dx.doi.org/10.1111/j.1464-5491.2008.02428.x

[11] Camilleri, M., Bharucha, A.E. and Farrugia, G. (2011) Epidemiology, Mechanisms, and Management of Diabetic Gastroparesis. Clinical Gastroenterology and Hepatology, 9, 5-12. http://dx.doi.org/10.1016/j.cgh.2010.09.022

[12] Bertin, E., Schneider, N., Abdelli, N., et al. (2001) Gastric Emptying Is Accelerated in Obese Type 2 Diabetic Patients without Autonomic Neuropathy. Diabetes \& Metabolism, 27, 357-364.

[13] Horowitz, M., Wishart, J.M., Jones, K.L. and Hebbard, G.S. (1996) Gastric Emptying in Diabetes: An Overview. Diabetic Medicine, 13, S16-S22.

[14] Shyangdan, D.S., Royle, P.L., Clar, C., Sharma, P. and Waugh, N.R. (2010) Glucagon-Like Peptide Analogues for Type 2 Diabetes Mellitus: Systematic Review and Meta-Analysis. BMC Endocrine Disorders, 10, 20. http://dx.doi.org/10.1186/1472-6823-10-20

[15] Malik, M., Bakir, A., Abi Saab, B., Roglic, G. and King, H. (2005) Glucose Intolerance and Associated Factors in the Multi-Ethnic Population of the United Arab Emirates: Results of a National Survey. Diabetes Research and Clinical Practice, 69, 188-195. http://dx.doi.org/10.1016/j.diabres.2004.12.005

[16] Saadi, H., Carruthers, S.G., Nagelkerke, N., et al. (2007) Prevalence of Diabetes Mellitus and Its Complications in a Population-Based Sample in Al Ain, United Arab Emirates. Diabetes Research and Clinical Practice, 78, 369-377. http://dx.doi.org/10.1016/j.diabres.2007.04.008

[17] International Diabetes Federation (2003) Diabetes Atlas. 2nd Edition, Brussels.

[18] Winge, K., Rasmussen, D. and Werdelin, L.M. (2003) Constipation in Neurological Diseases. Journal of Neurology, Neurosurgery \& Psychiatry, 74, 13-19. http://dx.doi.org/10.1136/jnnp.74.1.13

[19] Darwiche, G., Almér, L.O., Björgell, O., Cederholm, C. and Nilsson, P. (1999) Measurement of Gastric Emptying by Standardized Real-Time Ultrasonography in Healthy Subjects and Diabetic Patients. Journal of Ultrasound in Medicine, 18, 673-682.

[20] Darwiche, G., Björgell, O., Thorsson, O. and Almér, L.O. (2003) Correlation between Simultaneous Scintigraphic and 
Ultrasonographic Measurement of Gastric Emptying in Patients with Type 1 Diabetes Mellitus. Journal of Ultrasound in Medicine, 22, 459-466.

[21] Calbet, J.A. and MacLean, D.A. (1997) Role of Caloric Content on Gastric Emptying in Humans. The Journal of Physiology, 498, 553-559.

[22] Smout, A.J.P.M. and Akkermans, L.M.A. (1992) Gastro-Oesophageal Reflux Disease. In: Smout, A.J.P.M. and Akkermans, L.M.A., Eds., Normal and Disturbed Motility of the Gastrointestinal Tract, Wrightson Biomedical, Petersfield, 67-86.

[23] Peracchi, M., Gebbia, C., Ogliari, C., et al. (2000) Influence of Caloric Intake on Gastric Emptying of Solids Assessed by 13C-Octanoic Acid Breath Test. Scandinavian Journal of Gastroenterology, 35, 814-818. http://dx.doi.org/10.1080/003655200750023174

[24] Hellström, P.M., Grybäck, P. and Jacobsson, H. (2006) The Physiology of Gastric Emptying. Best Practice \& Research Clinical Anaesthesiology, 20, 397-407. http://dx.doi.org/10.1016/j.bpa.2006.02.002

[25] Moragas, G., Azpiroz, F., Pavia, J. and Malagelada, J.R. (1993) Relations among Intragastric Pressure, Postcibal Perception, and Gastric Emptying. American Journal of Physiology, 264, G1112-G1117.

[26] Buysschaert, M., Donckier, J., Dive, A., Ketelslegers, J.M. and Lambert, A.E. (1985) Gastric Acid and Pancreatic Polypeptide Responses to Sham Feeding Are Impaired in Diabetic Subjects with Autonomic Neuropathy. Diabetes, 34, 1181-1185. http://dx.doi.org/10.2337/diab.34.11.1181

[27] Nakamura, T., Takebe, K., Imamura, K., et al. (1994) Decreased Gastric Secretory Functions in Diabetic Patients with Autonomic Neuropathy. The Tohoku Journal of Experimental Medicine, 173, 199-208. http://dx.doi.org/10.1620/tjem.173.199

[28] Undeland, K.A., Hausken, T., Svebak, S., Aanderud, S. and Berstad, A. (1996) Wide Gastric Antrum and Low Vagal Tone in Patients with Diabetes Mellitus Type 1 Compared to Patients with Functional Dyspepsia and Healthy Individuals. Digestive Diseases and Sciences, 41, 9-16. http://dx.doi.org/10.1007/BF02208577

[29] Rathmann, W., Enck, P., Frieling, T. and Gries, F.A. (1991) Visceral Afferent Neuropathy in Diabetic Gastroparesis. Diabetes Care, 14, 1086-1089. http://dx.doi.org/10.2337/diacare.14.11.1086

[30] Krishnan, B., Babu, S., Walker, J., Walker, A.B. and Pappachan, J.M. (2013) Gastrointestinal Complications of Diabetes Mellitus. World Journal of Diabetes, 4, 51-63. http://dx.doi.org/10.4239/wjd.v4.i3.51

[31] Nilsson, P.H. (1996) Diabetic Gastroparesis: A Review. Journal of Diabetes and Its Complications, 10, 113-122. http://dx.doi.org/10.1016/1056-8727(96)00001-3

[32] Horowitz, M., Maddern, G.J., Chatterton, B.E., Collins, P.J., Harding, P.E., Shearman, D.J. (1984) Changes in Gastric Emptying Rates with Age. Clinical Science (London), 67, 213-218.

[33] Bennink, R., Peeters, M., Van den Maegdenbergh, V., et al. (1998) Comparison of Total and Compartmental Gastric Emptying and Antral Motility between Healthy Men and Women. European Journal of Nuclear Medicine, 25, 12931299. http://dx.doi.org/10.1007/s002590050298

[34] Córdova-Fraga, T., De la Roca-Chiapas, J.M., Solís, S., et al. (2008) Gender Difference in the Gastric Emptying Measured by Magnetogastrography Using a Semi-Solid Test Meal. Acta Gastroenterologica Latinoamericana, 38, 240-245.

[35] Wright, R.A., Krinsky, S., Fleeman, C., Trujillo, J. and Teague, E. (1983) Gastric Emptying and Obesity. Gastroenterology, 84, 747-751.

[36] Jones, T.F., Lin, Z., Sarosiek, I., Moncure, M. and McCallum, R.W. (2001) Assessment of Gastric Emptying and Myoelectric Activity in the Morbidly Obese Patients. Gastroenterology, 120, A1500.

[37] Naeslund, E. and Hellstroem, M. (1998) Glucagon-Like Peptide-1 in the Pathogenesis of Obesity. Drug News \& Perspectives, 11, 92. http://dx.doi.org/10.1358/dnp.1998.11.2.659947 


\section{Abbreviations}

BMI = Body Mass Index,

$\mathrm{DM}=$ Diabetes Mellitus,

$\mathrm{GE}=$ Gastric Emptying,

GER = Gastric Emptying Rate,

$\mathrm{GI}=$ Gastrointestinal,

GLP-1 = Glucagon-Like-Peptide-1,

HbA1c = glycosylated haemoglobin,

IHD = Ischaemic Heart Disease,

RCDR = Rashid Centre for Diabetes and Research,

UAE $=$ United Arab Emirates. 